\title{
FACTORS INFLUENCING THE USE OF BED NETS IN MBARARA MUNICIPALITY OF UGANDA
}

\author{
FRED NUWAHA \\ Health Services Sector, Bushenyi Local Government, Bushenyi, Uganda
}

\begin{abstract}
In order to identify independent predictors for bed net use, respondents from 643 households selected randomly from 21 clusters were interviewed in Mbarara municipality, Uganda. Respondents answered questions about demographic characteristics, social economic conditions, causes and transmission of malaria, beliefs about severity and complications of malaria, malaria morbidity and health care-seeking behavior, perceived control of malaria prevention, beliefs about utility of bed nets, perceived susceptibility to malaria, and whether they use bed nets or not. Univariate and multivariate logistic regression analyses were used to identify predictors for bed net use. Fifty-five percent (356 of 643) of the households had bed net users. The independent factors that favored bed net use were as follows: 1) age $<30$ years, 2) ownership of a television, 3) having mosquito nets in ventilators of the house, 4) being a skilled worker or a professional, or owning a major business, 5) living in a permanent house, 6) believing that bed nets prevent malaria, 7) believing that bed nets are worth their cost, 8) not believing that convulsions cannot be cured by modern medicine, and 9) believing that bed nets are not expensive. The strongest predictors of bed net use are living in a permanent house and agreeing that bed nets are worth their cost, with adjusted odds ratios of 4.29 (95\% confidence interval, 2.76-6.71) and 3.93 (95\% confidence interval, 2.5-26.13), respectively. These data suggest that in order to increase the use of bed nets, the price of bed nets needs to be reduced and educational messages that stress the favorable use of bed nets need to be increased.
\end{abstract}

\section{INTRODUCTION}

On a global scale, malaria causes an estimated 500 million clinical cases and $\sim 2.6$ million deaths annually, with $>90 \%$ of the cases of malaria shouldered by inhabitants of lowincome countries of sub-Saharan Africa. ${ }^{1}$ Measures for malaria control include chemotherapy, chemoprophylaxis, preventing vector contact with people, and vector control. The primary approach to malaria control in sub-Saharan Africa has been chemotherapy. However, the provision of effective chemotherapy, which had been mainstay of malaria control in countries such as Uganda, is now hampered by the emergence and spread of chloroquine-resistant Plasmodium falciparum. $^{2}$

Bed nets (mosquito nets) are an efficacious strategy of malaria control in selected areas. Insecticide-impregnated bed nets significantly reduce mortality and morbidity, as well as the incidence of severe malaria. ${ }^{3-7}$ They are also cost effective, ${ }^{8,9}$ and if used widely, they may delay the spread of chloroquine resistance. The use of bed nets is therefore a priority for malaria control in sub-Saharan Africa. The widespread use of impregnated bed nets is, however, limited by the absence of a sustainable mechanism for insecticide retreatment, low rates of usage (especially of insecticide-impregnated bed nets), and concerns regarding cost. ${ }^{10-12}$ An understanding of the factors influencing bed net usage is therefore a prerequisite for designing strategies aimed at improved bed net use. The current report describes factors influencing bed net usage in an urban area of Uganda where no project on improved bed net usage has been undertaken.

\section{MATERIALS AND METHODS}

This population-based cross-sectional survey was carried out in Mbarara municipality in southwestern Uganda. The municipality has an estimated 100,000 people on the basis of the 1991 national census, and is divided administratively into third-level local councils (LC3s; Kamukuzi, Kakoba, and Nyamitanga), 6 wards (second-level local councils, or LC2s), 50 first-level local councils (LC1s), and $\sim 20,000$ households. Approximately $25 \%$ of the population is aged $<5$ years.

The municipality includes hills and valleys and is mesoendemic for malaria. Malaria infections and morbidity have seasonal peaks after rains in March-May and in September-December. Epidemics occur about every 4 years. The main malaria treatment facilities are provided by Mbarara Hospital, which is the teaching hospital for Mbarara University. In each of the 3 divisions of the municipality, there is a government dispensary that provides primary treatment of minor illnesses. There are also private clinics and nursing homes throughout the municipality. Bed nets are sold mainly by private traders; the price is determined by market forces. On average, a nonimpregnated net costs $\sim 10,000-20,000$ Ugandan shillings ( US\$6-12). The cost of an impregnated net ranges 20,000-30,000 Ugandan shillings. Messages promoting the use of bed nets are commonly relayed on the 2 FM radio stations that are located in the town. These messages were particularly intensified after the disastrous 1998 malaria epidemic.

Selection of study participants. All households located in the municipality were included in the study population. Twenty-one LC1s with $\sim 30$ households each were chosen for the study. The municipality was first stratified into divisions, then from a list of LC1s, households were selected in proportion to the population size of each division by use of a table of random numbers. Starting in the center of each LC1, a stick was spun, and the orientation of the stick determined the direction followed by interviewers. If there was nobody to interview at home, the next household was visited. Less than $5 \%$ of the households initially selected did not have anybody to interview, possibly because most of the interviews were done on Sundays, when people stay at home.

Data collection instruments. A precoded, pretested questionnaire was administered to the head of household or 
TABLE 1

Distribution of bed net users and nonusers

\begin{tabular}{|c|c|c|c|c|}
\hline Respondent & No. users $(\%)$ & $\begin{array}{c}\text { No. } \\
\text { nonusers (\%) }\end{array}$ & $\begin{array}{c}\text { Crude odds ratio } \\
\text { (95\% confidence interval) }\end{array}$ & $P$ value \\
\hline Is head of household & $132(37)$ & $117(41)$ & $0.86(0.62-1.78)$ & 0.38 \\
\hline Is female & $263(74)$ & $208(73)$ & $1.07(0.76-1.52)$ & 0.77 \\
\hline Lived in Mbarara for $<5$ years & $155(44)$ & $121(42)$ & $1.06(0.77-1.45)$ & 0.78 \\
\hline Is $<30$ years of age & $235(66)$ & $165(58)$ & $1.44(1.04-1.98)$ & 0.03 \\
\hline Is of Banyankole ethnicity & $234(66)$ & $188(66)$ & $1.01(0.73-1.40)$ & 1.00 \\
\hline Is married & $277(78)$ & $224(78)$ & $0.99(0.68-1.43)$ & 1.00 \\
\hline Has $<5$ people in household & $208(58)$ & $197(69)$ & $0.64(0.46-0.89)$ & 0.19 \\
\hline Has children $<5$ years & $282(69)$ & $214(65)$ & $1.30(0.90-2.33)$ & 0.16 \\
\hline Has children $<10$ years & $318(89)$ & $245(85)$ & $0.70(0.43-1.15)$ & 0.19 \\
\hline Has pregnant woman in household & $70(20)$ & $60(21)$ & $0.98(0.56-2.31)$ & 0.63 \\
\hline Lives in Kakoba or Kamukuzi division & $206(58)$ & $135(47)$ & $1.83(1.22-2.76)$ & 0.003 \\
\hline House is located in low-lying area & $96(27)$ & $72(25)$ & $1.08(0.76-1.54)$ & 0.72 \\
\hline Religion is Protestant & $189(53)$ & $115(40)$ & $1.69(1.23-2.31)$ & 0.001 \\
\hline
\end{tabular}

spouse between July 11 and 25, 1999, by trained Mbarara University students accompanied by heads of LC1s. Five percent of all questionnaires selected randomly were repeated by a second interviewer.

Dependent variable. In this study, the criterion for bed net usage was having at least one bed net in the household. If there was no bed net in the household, it was labeled nonuser. Households were considered users regardless of whether or not the net was actually used or the way in which it was used. Thus, what was actually measured was ownership rather than use of a bed net. A household was defined as a group of people who cook and share their principal meals together.

Independent variables. The independent variables were age, ethnic background, religion, marital status, ownership of a radio, ownership of television, type of house, occupation of respondent and spouse, education level of respondent and of spouse, perceived cause of malaria, perceived severity and complications attributable to malaria, health beliefs influencing the use of bed nets, perceived susceptibility to malaria, self-reported malaria morbidity in the previous 2 weeks, and seeking health care for malaria.

Sample size. The study was aimed at interviewing at least 250 households that used bed nets and at least 250 who did not use bed nets. This sample size is large enough to identify determinants of bed net usage, with a relative risk of 3 or more unless the determinants are extremely common or uncommon. This sample size also has a good chance of identifying determinants with a relative risk of $2-3$ if prevalence in the study population is $20-70 \% .^{13}$ The prevalence of bed net usage estimated from mothers attending the prenatal clinic at Mbarara University teaching hospital was 45\% (95\% confidence interval [CI], 35-55) (Nuwaha, unpublished data). About $95 \%$ of all mothers in the municipality attend prenatal clinics at least once.

Ethical considerations. The research was approved by the research and ethics committees of the Faculty of Medicine, Mbarara University of Science and Technology, and informed consent was obtained before interviews took place.

Data analysis. Univariate analysis with the chi-square or Fisher's exact test by 2-tailed tests was used to compare proportions. Crude odds ratios and the 95\% CI were calculated after univariate analysis. To identify independent predictors of bed net use, stepwise multivariate logistic regres- sion procedures were used. All variables that were significant via univariate analysis $(P<0.05)$ were used in the multivariate analyses. Forward-selection and backwardelimination methods were used to enhance the robustness of the model. Both procedures produced the same model. Variables that did not improve the fit of the regression (as measured by log likelihood) were left out. Adjusted odds ratios were calculated after multivariate analysis. The statistical software packages Epi Info version $6^{13}$ and SPSS/PC ${ }^{14}$ were used in the analyses.

\section{RESULTS}

The total number of households surveyed was 643. Of these, 356 households (55\%, 95\% CI, 51-59) had at least one bed net, and $287(45 \%)$ had no bed net. A total of 471 of the respondents $(74 \%)$ were women. Seventy-five (12\%) of the households were headed by women. Of the 643 households, $130(20 \%)$ included a pregnant woman, and 432 $(67 \%)$ households included at least one child aged $<5$ years. The mean family size was 5.2 , with a standard deviation (SD) of 3.3. The mean number of children $<5$ years was 1.3 per household, with a SD of 1.1 , and for children aged $<10$ years, the mean was 1.9 , with a SD of 1.3 . Of the 643 respondents, $249(38 \%)$ were heads of household, and 394 were spouses of heads of household. A total of 367 (57\% of the households) had lived in Mbarara for $>5$ years.

Of the 356 households with bed nets, 105 (16.3\%) had one bed net, $118(18.4 \%)$ had 2 bed nets, $62(9.6 \%)$ had 3 bed nets, and $73(11.3 \%)$ had $4-8$ nets. Only 44 of 356 households $(12 \%)$ reported that their bed nets were insecticide impregnated. Users of impregnated bed nets did not differ from users of nonimpregnated bed nets in terms of age, socioeconomic status, or health beliefs about malaria. Among the nonusers, 52 of $287(18 \%)$ had used bed nets in the past but were currently not using them. Reasons for stopping included the cost of new bed nets (26 of 52, 50\%), reduced risk of exposure to mosquitoes $(n=11,21 \%)$, was inconvenient on hot nights $(n=9,18 \%)$, and children outgrew bed nets $(n=6,11 \%)$.

Demographic characteristics. Table 1 shows the distribution of bed net users and nonusers in terms of age, type and sex of respondent, length of residence, ethnicity, family structure, marital status, location of dwelling, and religion. 
TABLE 2

Distribution of bed net users and nonusers according to socioeconomic factors

\begin{tabular}{|c|c|c|c|c|}
\hline Respondent & No. users (\%) & No. nonusers (\%) & $\begin{array}{c}\text { Crude odds ratio } \\
\text { (95\% confidence interval) }\end{array}$ & $P$ value \\
\hline Owns a radio & $334(94)$ & $249(87)$ & $2.31(1.34-4.01)$ & 0.003 \\
\hline Owns a television set & $203(57)$ & $71(25)$ & $4.04(2.87-5.67)$ & $<0.001$ \\
\hline Lives in permanent house & $272(75)$ & $98(34)$ & $6.24(4.42-8.82)$ & $<0.001$ \\
\hline House has $>2$ bedrooms & $172(48)$ & $89(31)$ & $2.08(1.49-2.86)$ & $<0.001$ \\
\hline Windows have mosquito screening & $117(33)$ & $55(19)$ & $2.06(1.42-2.98)$ & $<0.001$ \\
\hline Ventilators have mosquito screening & $195(55)$ & $87(38)$ & $2.81(2.03-3.91)$ & $<0.001$ \\
\hline Uses electricity for cooking & $44(12)$ & $19(7)$ & $1.99(1.13-3.49)$ & 0.02 \\
\hline Uses electricity for lighting & $276(78)$ & $149(52)$ & $3.20(2.27-4.40)$ & $<0.001$ \\
\hline Has $\geq 11$ years of formal education & $171(48)$ & $57(20)$ & $3.85(2.63-5.26)$ & $<0.001$ \\
\hline Spouse has $\geq 11$ years of formal education & $225(63)$ & $114(45)$ & $2.63(1.89-3.57)$ & $<0.001$ \\
\hline Reads in vernacular & $321(90)$ & $231(81)$ & $2.22(1.41-3.50)$ & $<0.001$ \\
\hline Reads English & $273(77)$ & $137(48)$ & $3.60(2.57-5.04)$ & $<0.001$ \\
\hline Occupation (skilled worker, major business/professional) & $206(58)$ & $101(35)$ & $2.50(1.85-3.57)$ & $<0.001$ \\
\hline Occupation of spouse (skilled worker, major business/professional) & $290(81)$ & $160(56)$ & $3.10(2.45-5.00)$ & $<0.001$ \\
\hline
\end{tabular}

Of these demographic variables, bed net use was favored by those aged $<30$ years, those living in the Kakoba or Kamukuzi divisions, and those who were Protestant. Type and sex of respondent, family structure, marital status, length of residence in municipality, and location of dwelling did not influence use of bed nets.

Socioeconomic variables. The distribution of socioeconomic variables is shown in Table 2. The use of bed nets was favored in measures of socioeconomic index, namely ownership of radio or television, living in a permanent house with mosquito netting in ventilators and windows, respondent or spouse being a skilled worker or professional or owning a major business, respondent or spouse having at least 11 years of formal education, and being able to read in vernacular or in English.

Perceived causes of malaria severity and complications. Perceived causes of malaria, severity, and complications are shown in Table 3. People who used bed nets were more likely to believe the following: that malaria was caused by mosquitoes; that malaria is severe in some people; that malaria is not caused by fresh fruits and/or maize; that convulsions could be cured by modern medicine; and that big spleen disease could not be cured by traditional medicine. Saying that malaria is caused by bad water, witchcraft, or staying near somebody with malaria did not influence bed net usage.

Malaria morbidity and health care-seeking behavior. Malaria morbidity and health care-seeking behavior are shown in Table 4. It appears that bed net usage does not influence malaria morbidity at the household level. Ownership of bed nets was also not associated with choice of health care provider in the modern sector. However, nonusers were more likely to use traditional medicine for a malaria episode in the last 2 weeks and less likely to undergo a blood examination. Nonusers of bed nets were also more likely to have used traditional medicine for prevention or treatment of malaria.

Perceived control of malarial prevention and beliefs about bed nets. Respondents were asked if prevention of malaria depends on the respondent, chance, respondent's spouse, or other people or things and their beliefs toward bed nets. The results of these beliefs are shown in Table 5. Respondents saying that preventing malaria depends on the self and not on chance favored bed net usage. Users of bed nets were more likely to believe that bed nets prevent mosquito bites, that bed nets reduced the risk of malaria, and that bed nets are worth their cost.

Perceived risks of malaria. Respondents were asked

TABLE 3

Distribution of bed net users and nonusers according to perceived causes, severity, and complications of malaria

\begin{tabular}{|c|c|c|c|c|}
\hline Variable & No. users $(\%)$ & $\begin{array}{l}\text { No. nonusers } \\
(\%)\end{array}$ & $\begin{array}{c}\text { Crude odds ratio } \\
\text { (95\% confidence interval) }\end{array}$ & $P$ value \\
\hline \multicolumn{5}{|l|}{ Causes of malaria } \\
\hline Mosquito & $347(98)$ & $266(93)$ & $3.04(1.37-6.75)$ & 0.007 \\
\hline Breathing bad air & $101(28)$ & $97(34)$ & $0.76(0.55-1.08)$ & 0.16 \\
\hline Contact with a malaria patient & $177(50)$ & $154(54)$ & $0.85(0.63-1.17)$ & 0.36 \\
\hline Witchcraft & $30(8)$ & $33(12)$ & $0.71(0.42-1.19)$ & 0.24 \\
\hline Eating fresh fruits or maize & $90(25)$ & $96(33)$ & $0.67(0.47-0.95)$ & 0.03 \\
\hline \multicolumn{5}{|l|}{ Complications of malaria (agrees) } \\
\hline Malaria is more severe in children & $317(89)$ & $248(86)$ & $1.27(0.80-2.05)$ & 0.37 \\
\hline Malaria is more severe in pregnant women & $299(84)$ & $238(83)$ & $1.08(0.71-1.64)$ & 0.80 \\
\hline Some people are more prone to getting malaria than others & $263(74)$ & $172(60)$ & $1.89(1.35-2.64)$ & $<0.001$ \\
\hline Malaria causes convulsions & $300(84)$ & $238(83)$ & $1.10(0.73-1.68)$ & 0.72 \\
\hline Convulsions cannot be cured by modern medicine & $164(46)$ & $163(57)$ & $0.65(0.48-0.89)$ & 0.009 \\
\hline Malaria causes anemia & $316(89)$ & $257(90)$ & $0.92(0.56-1.52)$ & 0.85 \\
\hline Malaria causes big spleen disease & $245(69)$ & $214(75)$ & $0.75(0.53-1.07)$ & 0.13 \\
\hline Big spleen diseases can be cured by traditional medicine & $238(67)$ & $221(77)$ & $0.60(0.42-0.87)$ & 0.006 \\
\hline
\end{tabular}


TABLE 4

Distribution of bed net users and nonusers according to malaria morbidity and healthy care-seeking behavior

\begin{tabular}{|c|c|c|c|c|}
\hline Variable & No. users (\%) & $\begin{array}{l}\text { No. nonusers } \\
(\%)\end{array}$ & $\begin{array}{l}\text { Crude odds ratio } \\
\text { (95\% confidence interval) }\end{array}$ & $P$ value \\
\hline $\begin{array}{l}\text { Malaria morbidity of any family member currently or in } \\
\text { previous } 2 \text { weeks }\end{array}$ & $162(46)$ & $147(51)$ & $0.81(0.58-1.09)$ & 0.17 \\
\hline \multicolumn{5}{|l|}{ Treatment from*: } \\
\hline Government health unit & $76(39)$ & $52(37)$ & $1.07(0.68-1.67)$ & 0.86 \\
\hline Private clinic & $126(65)$ & $81(58)$ & $1.31(0.84-2.04)$ & 0.29 \\
\hline Drugstore or pharmacy & $55(28)$ & $44(32)$ & $0.85(0.53-1.36)$ & 0.58 \\
\hline Self-treatment & $31(16)$ & $31(22)$ & $0.66(0.38-1.15)$ & 0.18 \\
\hline Traditional medicine & $19(10)$ & $34(25)$ & $0.33(0.18-0.61)$ & $<0.001$ \\
\hline Other treatment & $12(6)$ & $8(6)$ & $1.07(0.43-2.70)$ & 1.00 \\
\hline No treatment & $1(0.5)$ & $5(4)$ & $0.14(0.02-1.20)$ & 0.09 \\
\hline Know which drugs were taken (yes) & $166(85)$ & $111(80)$ & $1.44(0.81-2.56)$ & 0.26 \\
\hline Blood examination done (yes) & $126(78)$ & $74(51)$ & $1.57(1.12-2.22)$ & 0.011 \\
\hline Ever used herbs for prevention or treatment of malaria (yes) & $138(39)$ & $148(52)$ & $0.59(0.43-0.81)$ & 0.002 \\
\hline
\end{tabular}

* More than one kind of treatment was taken by some respondents.

about the chance of them or a family member getting malaria and whether anybody in the family has ever been admitted for malaria or had died as a result of malaria. The results are shown in Table 6. Perceived reduced chance of respondent or family member in getting malaria favored bed net usage. However, having a family member who had died of malaria or who had been admitted for malaria did not influence bed net use.

Independent predictors of bed net use. Table 7 shows the independent predictors of bed net usage. The factors that favor bed net use are being $<30$ years of age, ownership of television, having mosquito nets in ventilators of the house, respondent or respondent's spouse being a skilled worker, professional, or owning major business, living in a permanent house, believing that bed nets prevent malaria, believing that bed nets are worth their cost, not believing that convulsions cannot be cured by modern medicine, and believing that bed nets are not expensive. These 10 variables predicted bed net use, with $293(82 \%)$ of 356 of bed net users correctly classified and $205(71 \%)$ of 287 of the nonusers being correctly classified. Overall, $498(77 \%)$ of 643 of the households were correctly classified. This classification was significantly different from that observed by chance ( $-2 \log$ likelihood ratio 64, 632 degrees of freedom [df] and significance 0.39 ; model chi-square $243,10 \mathrm{df}$ and significance $<0.001$; and goodness of fit 639, $632 \mathrm{df}$ and significance 0.43 ). The strongest predictors of bed net use are living in a permanent house and agreeing that bed nets are worth their cost, with adjusted odds ratios of 4.29 and 3.93, respectively.

\section{DISCUSSION}

This study estimated the prevalence and factors influencing use of bed nets in an urban sample. The prevalence of bed net usage in this study is higher than that reported in other areas of Uganda, including Ndeeba, Kampala (Makanga, unpublished data), and in Fort-portal and Bundibugyo districts (Killian, unpublished data). A possible explanation was that in Ndeeba, Kampala, the study concentrated on a slum with households in a low socioeconomic class. The study in Fort-portal was in a rural area where the standard of living is much lower than in Mbarara municipality. Another explanation is that the current study was performed 8 months after a major malaria epidemic in southwestern Uganda. It is possible that this epidemic, with one of the highest mortality rates recorded, could have motivated people to use bed nets. During and after the epidemic, the health authorities intensified the campaign for bed net usage on FM radio stations. Furthermore, the malaria epidemic attributed to the El Niño weather phenomenon could have increased nuisance bites from the increased mosquito populations, thereby motivating people to use bed nets.

The independent factors influencing bed nets can be

TABLe 5

Distribution of bed net users and nonusers according to health beliefs

\begin{tabular}{|c|c|c|c|c|}
\hline Variable & No. users (\%) & $\begin{array}{l}\text { No. nonusers } \\
(\%)\end{array}$ & $\begin{array}{c}\text { Crude odds ratio } \\
\text { (95\% confidence interval) }\end{array}$ & $P$ value \\
\hline \multicolumn{5}{|c|}{$\begin{array}{l}\text { Preventing myself and my family from getting } \\
\text { malaria depends on: }\end{array}$} \\
\hline Myself & $280(79)$ & $194(68)$ & $1.77(1.24-2.52)$ & 0.002 \\
\hline Chance & $129(36)$ & $131(46)$ & $0.68(0.49-0.93)$ & 0.02 \\
\hline My spouse & $111(31)$ & $81(28)$ & $1.15(0.82-1.62)$ & 0.47 \\
\hline Other people/things & $108(30)$ & $76(27)$ & $1.21(0.86-1.71)$ & 0.32 \\
\hline \multicolumn{5}{|l|}{ Beliefs about bed nets } \\
\hline Bed nets prevent malaria & $320(90)$ & $213(74)$ & $3.09(2.00-4.77)$ & $<0.001$ \\
\hline Bed nets prevent mosquito bites & $351(99)$ & $263(92)$ & $6.41(2.41-17.01)$ & $<0.001$ \\
\hline Bed nets are expensive & $218(61)$ & $201(70)$ & $0.68(0.49-0.94)$ & 0.0025 \\
\hline Bed nets are worth their cost & $303(85)$ & $169(70)$ & $3.99(2.74-2.81)$ & $<0.001$ \\
\hline Bed nets are inconvenient to use & $114(32)$ & $100(35)$ & $0.88(0.63-1.22)$ & 0.49 \\
\hline
\end{tabular}


TABLE 6

Distribution of bed net users and nonusers according to perceived malaria risk

\begin{tabular}{|c|c|c|c|c|}
\hline Variable & No. users $(\%)$ & $\begin{array}{l}\text { No. nonusers } \\
(\%)\end{array}$ & $\begin{array}{l}\text { Crude odds ratio } \\
\text { (95\% confidence interval) }\end{array}$ & $P$ value \\
\hline My chances of getting malaria are very high/high & $175(49)$ & $167(58)$ & $0.69(0.51-0.95)$ & 0.03 \\
\hline The chances of a family member getting malaria are very high/high & $193(54)$ & $182(63)$ & $0.68(0.50-0.94)$ & 0.02 \\
\hline Family member ever been admitted for malaria (yes) & $113(32)$ & $101(35)$ & $0.86(0.62-1.19)$ & 0.40 \\
\hline Family member ever died of malaria (yes) & $16(5)$ & $20(7)$ & $0.63(0.32-1.24)$ & 0.24 \\
\hline
\end{tabular}

grouped under 3 headings, namely: younger age, indicators of high socioeconomic class, and favorable beliefs (psychosocial variables) toward the use of bed nets. Indicators of socioeconomic status are not well developed for low-income countries; therefore, proxy measures, such as ownership of property, level of education, occupation, place of residence, type of housing, and fuel used for cooking and lighting, have been used in Uganda ${ }^{15}$ and in other low-income countries. ${ }^{16}$

The influence of age on bed nets use was surprising and may indicate that younger people are more likely to heed health education messages. Also, according to a theory of adoption of innovations commonly used in applied social psychology, young people are likely to be innovators or early adopters of preventive technologies. ${ }^{17}$ On the other hand, young families are more likely to have young children and pregnant women and are therefore more likely to use bed nets. However, evidence from the present study does not support this reasoning: households with children aged $<5$ years or with pregnant women did not have a higher rate of bed net use.

The influence of high socioeconomic class on bed net usage was expected and not surprising. People in a high social economic class are likely to have more disposable income that can be used for purchase of bed nets. Furthermore, they are likely to have more favorable beliefs towards the use of bed nets and are therefore likely to pay attention to health education messages in both print and electronic media. The cost of one nonimpregnated bed net averages $\sim 15,000$ Ugandan shillings, which is $\sim$ US\$10. Given that the average monthly income of a Ugandan worker is $\sim 70,000$ Ugandan shillings, there is not much savings to invest in the purchase of bed nets. Extrapolation of these results in rural areas where $80 \%$ of Ugandans live with even less disposable income implies that bed net usage in rural areas is even lower than in Mbarara municipality.
In the current study, favorable beliefs were very important in predicting use of bed nets. Users were more likely to believe that bed nets prevent malaria and are not expensive, and more importantly, they were more likely to believe that bed nets are worth the cost. These data are supported by research from applied social psychology and health education, where attitudinal and self-efficacy beliefs of this nature are very important in influencing health-related behavior. ${ }^{18,19}$ According to social-psychological models, these beliefs are particularly important in behavior change because they could be targeted for modification that use health education or promotion or other appropriate methods..$^{20}$

Limitations of this study are mainly due to its cross-sectional nature. This means that it is difficult to establish cause and effect. For example, use of bed nets could lead the respondents to underestimate the risk for malaria. Nevertheless, this study provides useful information about bed net use that may be of practical importance.

Implications for intervention. These data suggest that in order to increase the use of bed nets, there is a need for more health education and promotion messages on the advantages of bed net use. Because beliefs were important distinguishing features between users and nonusers, it implies that such messages are relevant and need to be strengthened. Indeed, people need to be convinced that bed nets are worth the cost and that they are probably as important as shoes, clothes, radio, or television. If bed nets cannot be provided for all family members, they should at least be provided for children aged $<5$ years. Because $>87 \%$ of the respondents believed that malaria is more severe in children aged $<5$ years, this targeting of bed net use may be acceptable to this community.

Only $12 \%$ of the bed nets used in this community were reported to be impregnated with insecticide. There is a need to increase the use of impregnated bed nets, which give

TABLE 7

Independent predictors of bed net use in Mbarara Municipality of Uganda

\begin{tabular}{lc}
\hline \multicolumn{1}{c}{ Variable } & $\begin{array}{c}\text { Adjusted odds ratio } \\
\text { (95\% confidence interval) }\end{array}$ \\
\hline Age (<30 years) & $1.90(1.26-2.86)$ \\
Ownership of television set (yes) & $1.61(1.03-2.52)$ \\
Type of house (permanent) & $4.29(2.76-6.71)$ \\
Having mosquito netting in ventilators of house (yes) & $1.57(1.05-2.33)$ \\
Occupation of respondent (skilled, professional, major business versus semi- & \\
$\quad$ skilled, unskilled, housewife, none, petty business) & $1.78(1.20-2.63)$ \\
Occupation of spouse of respondent (skilled, professional, major business & 0.03 \\
$\quad$ versus semiskilled, unskilled, housewife, none, petty business) & $1.82(1.16-2.78)$ \\
Bed nets are expensive (disagree/agree) & $1.56(1.03-2.38)$ \\
Bed nets are worth their cost (agree/disagree) & $3.93(2.52-6.13)$ \\
Bed nets prevent malaria (agree/disagree) & $2.35(1.38-4.01)$ \\
Convulsions cannot be cured by modern medicine (disagree/agree) & $1.85(1.25-2.70)$ \\
\hline
\end{tabular}


greater protection against malaria than nonimpregnated bed nets. ${ }^{3}$ Moreover, impregnated bed nets also kill other household insects and pests and have a spillover effect, protecting those who do not use them, both in the household and in the community. ${ }^{9}$

Because indicators of high socioeconomic status influenced bed net use, there is a need to reduce the price of bed nets so they are affordable by members of lower socioeconomic classes. Measures for reducing prices include bulk purchasing, tax exemption, local tailoring, and instituting community-based distribution and reimpregnation mechanisms. ${ }^{21-23}$ The issue of a public subsidy for impregnated bed nets also needs to be seriously considered. ${ }^{8,9}$

Acknowledgments: I thank all research assistants who took part in the study and the study participants. The first version of this article was reviewed by Dr. Mulogo Edgar of the Department of Community Health, Mbarara University, Uganda.

Financial support: This work was supported by the Faculty of Medicine, Mbarara University of Science and Technology Research Fund.

Author's address and reprint requests: Fred Nuwaha, Directorate of Health Services, Bushenyi Local Government, P.O. Box 1043, Mbarara, Uganda.

\section{REFERENCES}

1. WHO, 1995. Vector Control for Malaria and Other MosquitoBorne Diseases. WHO Technical Report Series 857. Geneva, Switzerland: World Health Organization.

2. Bloland, Kazembe PN, Oloo AJ, Himonga B, Barat LM, Reubesh TK, 1998. Chloroquine in Africa: critical assessment and recommendations for monitoring and evaluating chloroquine therapy efficacy in Sub-Saharan Africa. Trop Med Int Health 3: 523-532.

3. Choi HW, Breman J, Teutsch SM, Luo S, Hightower AW, Sexton JD, 1995. The effectiveness of insecticide impregnated bed nets in reducing cases of malaria infection: a meta-analysis of published results. Am J Trop Med Hyg 52: 377-382.

4. Alonso PL, Lindsay SW, Armstrong-Schellenberg JRM, Keita K, Gomez P, Shenton EC, Hill AG, David PH, Fegan G, Cham K, Greenwood BM, 1993. The impact of the intervention on mortality and morbidity from malaria. Trans $R$ Soc Trop Med Hyg 87(Suppl. 2): 37-44.

5. D'Alessandro U, Olaleye BO, McGuire W, Langerock P, Bennet S, Aikins MK, Thomson MC, Cham MK, Cham BA, Greenwood BM, 1995. Mortality and morbidity from malaria in Gambia children after introduction of an impregnated bed net programme. Lancet 345: 479-483.

6. Binka FN, Kubaje A, Adjuik M, Williams MK, Lengeler C, Maude GH, Armah GE, Kajuhara B, Adiamah JH, Smith PG, 1996. Impact of permethrin impregnated bed nets on child mortality in Kassena Nankana district, Ghana: randomised controlled trial. Trop Med Int Health 1: 147-154.
7. Nevill CG, Some ES, Mung'ala VO, Muteme W, New L, Marsh K, Lengeler C, Snow RW, 1996. Insecticide treated bed nets reduce mortality and severe morbidity from malaria among children on the Kenyan Coast. Trop Med Int Health 1: 139146.

8. Evans D, Asene G, Kirigia J, 1997. Should governments subsidise the use of insecticide-impregnated bed nets in Africa? Implications and cost-effective analysis. Health Policy Plan 12: $107-114$.

9. Aikins MK, Fox-Rushby J, D'Alessandro WD, Mills A, Aikins M, Cham K, Bennet S, Greenwood BM, 1998. The Gambia national impregnated bed net programme: costs, consequences and net cost-effectiveness. Soc Sci Med 46: 181-191.

10. Marsh VM, Mutemi W, Some ES, Haaland A, Snow RW, 1996. Evaluating the community education programme of an insecticide-treated bed net trial on the Kenyan coast. Health Policy Plan 11: 280-291.

11. Snow RW, McCabe E, Mbogo CNM, Molyneux CS, Some ES, Vo Mung'ala Nevill CG, 1999. The effect of delivery mechanisms on the uptake of bed net re-impregnation in Kilifi district Kenya. Health Policy Plan 14: 18-25.

12. Cham MK, D'Alessandro U, Todd J, Benett S, Fegan G, Cham BA, Greenwood BM, 1996. Implementing a nation-wide insecticide-impregnated bed net programme in The Gambia. Health Policy Plan 11: 292-298.

13. Centers for Disease Control and Prevention, 1994. Epi Info, version 6. Atlanta, GA: Centers for Disease Control and Prevention.

14. Norusis MJ, 1998. SPSS/PC for the IBM PC/XT/AT. Chicago, IL: SPSS.

15. Cortinovis I, Vella V, Ndiku J, 1993. Construction of a socioeconomic index to facilitate analysis of health data in developing countries. Soc Sci Med 36: 1087-1097.

16. Barnhorn F, Adriaanse H, 1992. In search of factors responsible for non-compliance among tuberculosis patients in Wardha district, India. Soc Sci Med 34: 291-306.

17. Rogers EM, 1983 Diffusion of Innovations. New York: Free Press.

18. de Vries H, Dijkstra M, Kuhlman P, 1988. Self-efficacy: the third factor besides attitude and subjective norm as predictor of behaviour intentions. Health Educ Res 3: 273-282.

19. Ajzen I, 1991. The theory of planned behaviour. Org Beh Hum Dec Proc 50: 179-211.

20. Kok G, Schaalma H, De Vries H, Parcel G, Paulussen T, 1996. Social psychology and health education. Eur Rev Social Psychol 7: 241-282.

21. Gyapong M, Gyabong JO, Amankwa J, Asedem J, Sory E, 1996. Introducing insecticide impregnated bed nets in an area of low bed net usage: an exploratory study in north-eastern Ghana. Trop Med Int Health 1: 328-333.

22. Makemba AM, Winch PJ, Kamazima SR, Makame VR, Sengo F, Lubega PB, Minjas JN, Shiff CJ, 1995. Community based sale distribution and insecticide impregnation of mosquito nets in Bagamoyo district Tanzania. Health Policy Plan 10: 50-59.

23. Mills A, Fox-Rushby J, Aikins M, D'Alessnddro U, Cham K, Greenwood BM, 1994. Financing mechanisms for village activities in the Gambia and their implications for financing insecticide for bed net impregnation. J Trop Med Hyg 97: 325332 . 